\title{
Distribution of plant species and species-soil rela- tionship in the east central Gurbantunggut Desert, China
}

\author{
AN Ping ${ }^{1}$, LI Xiangjun ${ }^{2}$, ZHENG Yuanrun ${ }^{3}$, ENEJI A. Egrinya ${ }^{4}$, QIMAN Yunus ${ }^{5}$, \\ ZHENG Mingqing $^{1}$, INANAGA Shinobu ${ }^{6}$ \\ 1. Arid Land Research Center, Tottori University, Tottori 680-0001, Japan; \\ 2. Hebei Academy of Forestry Science, Shijiazhuang 050061, China; \\ 3. Laboratory of Quantitative Vegetation Ecology, Institute of Botany, CAS, Beijing 100093, China; \\ 4. Department of Soil Science, Faculty of Agriculture, Forestry and Wildlife Resources Management, University \\ of Calabar, Nigeria; \\ 5. College of Horticulture, Xinjiang Agricultural University, Urumqi 830052, China; \\ 6. Institute of Technologists, 333, Maetani, Gyouda-shi, Saitama 361-0038, Japan
}

\begin{abstract}
The distribution of plant species and relationships between species and soil factors in the east central part of Gurbantunggut Desert was studied to provide more insight into the flora and determine differences in vegetation across various parts of the desert. Two-way Cluster Analysis showed that the vegetation in the area could be divided into three groups, the first group was dominated by the shrub species, Ephedra przewalskii and the grass species, Carex physodes mainly in areas of flat grounds and gentle slopes; the second group was dominated by C. physodes, Artemisia songorica and A. xerophytica mainly on the slope of sand dunes and the third group was dominated by the shrub species, Haloxylon persicum mainly on the top of sand dunes. There was no difference in plant density between Groups 1 and 2 but there was a significant decrease in Group 3. Soil water under vegetation Group 3 was much lower than that in the other two groups at all soil depths. The EC, organic matter, total $\mathrm{P}$ and soluble $\mathrm{Na}, \mathrm{Ca}$ and $\mathrm{Mg}$ varied very similarly with soil water. Canonical correspondence analysis (CCA) satisfactorily assessed the species-soil relations in the area. The distribution of plant species was strongly correlated with the soil factors of water content, organic matter, EC and nutrients. The variations in species occurrence explained by the three CCA axes were about $70 \%$, indicating that some explanatory site variables may exist outside our studied parameters. Soil texture is suggested to be included in future studies to improve the explanation of CCA.
\end{abstract}

Keywords: distribution; plant species; soil; Gurbantunggut Desert; China

\section{Introduction}

The third biggest desert in the world, Gurbantunggut Desert in Northwest China, has fixed and semi-fixed sands and sand dunes. The stability of the desert resulted from combined

Received: 2013-03-28 Accepted: 2014-02-26

Author: An Ping, Associate Professor, E-mail: an.ping@alrc.tottori-u.ac.jp 
environmental factors such as the large size of the sands, which requires stronger winds to displace (Ji et al., 2000; Wang et al., 2005), accumulated snow and a frozen soil layer in winter, which keep the sands from being blown out by the strong wind and supply sufficient water for plant emergence and growth in the next spring (Qian et al., 2002; Zhang and Chen, 2002; Wei et al., 2003; Fan et al., 2012). Also, the biological soil crust in the area enhances the resistance of the sand surface to wind erosion and a favorable environment for seed germination and plant growth (Zhang et al., 2010). In addition, the well developed vegetation (Ji et al., 2000; Wang et al., 2003; Wang et al., 2005; Fan et al., 2012), especially the relatively high vegetation coverage during March-July which accounts for $55 \%-80 \%$ of the yearly wind (Ji et al., 2000; Wang et al., 2005) further stabilizes the desert sands. These reports clearly showed the significance of vegetation for the stability of the desert.

The vegetation of Gurbantunggut Desert has been widely studied in recent 10 years with respect to vegetation distribution and vegetation-environment relationships, vegetation patterns and species-environment relationships (Qian et al., 2007; Qian and Wu, 2008; Song et al., 2011; Fan et al., 2013; Zhang et al., 2013), relationships between vegetation pattern and topography (Xie and Liu, 2010), response of herbaceous species to snow variability (Fan et al., 2012), diversity of plant community (Zhao et al., 2010), plant diversity and spatial pattern of dominant population (Zhang et al., 2003; Tang et al., 2010), soil chemical properties supporting dominant species (Li et al., 2010; Li et al., 2011), environmental limitations on the recruitment of the plant species (Zhang et al., 2011), response of ephermal plants to water and heat (Wang et al., 2006; Chen et al., 2008) and grassland-environment relationship (Xu, 1998). However, the areas investigated in previous studies were all within the southern part of the desert which is close to the oasis zone where several millions of people reside. Therefore, this part is frequently disturbed by human activities and grazing. In previous studies, vegetation distribution and vegetation-environments relationships were discussed at either a very large scale of several hundred kilometers (300-600 km), very small scale of several hundred meters (60-200 m) or focused on specific species.

Gurbantunggut Desert covers an area of $4.88 \times 10^{4} \mathrm{~km}^{2}$ with $444 \mathrm{~km}$ from west to east and $231 \mathrm{~km}$ from north to south (Wang, 2003). We located the present study at a medium scale of about $10 \mathrm{~km} \times 10 \mathrm{~km}$ in the central part of the eastern Gurbantunggut Desert. This area is relatively far from the oasis zone and has been less studied or disturbed by human activities. The distribution of plant species and relationships between species and soil factors of the area were investigated to give more insight into the flora of the whole desert and to understand the differences in species distribution in different parts of the desert.

\section{Study area and methods}

\subsection{Location and description of study area}

Gurbantunggut Desert is the main body of Junggar basin. The geographical and meteorological characteristics of the desert have been well summarized (Wang et al., 2005; Wang et al., 2009; Song et al., 2011). The desert is a transitional zone between the Central Asian desert and Monggolian Gobi desert. A typical landscape of the desert is the north-south orientated longitudinal dunes with a length ranging from a few hundred meters to more than 10 $\mathrm{km}$ and a height of 10-50 m. Interdune areas are usually flat and the mid-lower part of the 
dune has a gentle slope. The crest usually has a 10-40 m wide mobile belt. Vegetation is typical of the desert flora of Central Asia. The vegetation and mobility of sand dunes has historically been sensitive to local climate conditions (Wang, 2003). The distribution of vegetation communities relates to the spatial variation of macro-ecoenvironment (local climate and landform) and the microhabitat heterogeneity of the sandy soils (soil nutrient, moisture, salt and $\mathrm{pH}$ ) has impact on the species composition and community structure (Qian et al., 2004).

As shown in Figure 1, the study area $\left(44^{\circ} 93^{\prime}-45^{\circ} 00^{\prime} \mathrm{N}, 88^{\circ} 54^{\prime}-88^{\circ} 70^{\prime} \mathrm{E}\right)$ was located in the east central part of Gurbantunggut Desert. The study area belongs to Jimsar County of Xinjiang Uygur Autonomous Region of China. The climatic and meteorological conditions of the area are similar with those of the whole desert, characterized by dry continental climate with scanty precipitation, high potential evaporation, strong wind, wide temperature range, short spring and autumn and long winter (Wang, 2003; Zhang et al., 2010; Song et al., 2011). The average monthly precipitation and temperature of the study area are given in Figure 2.

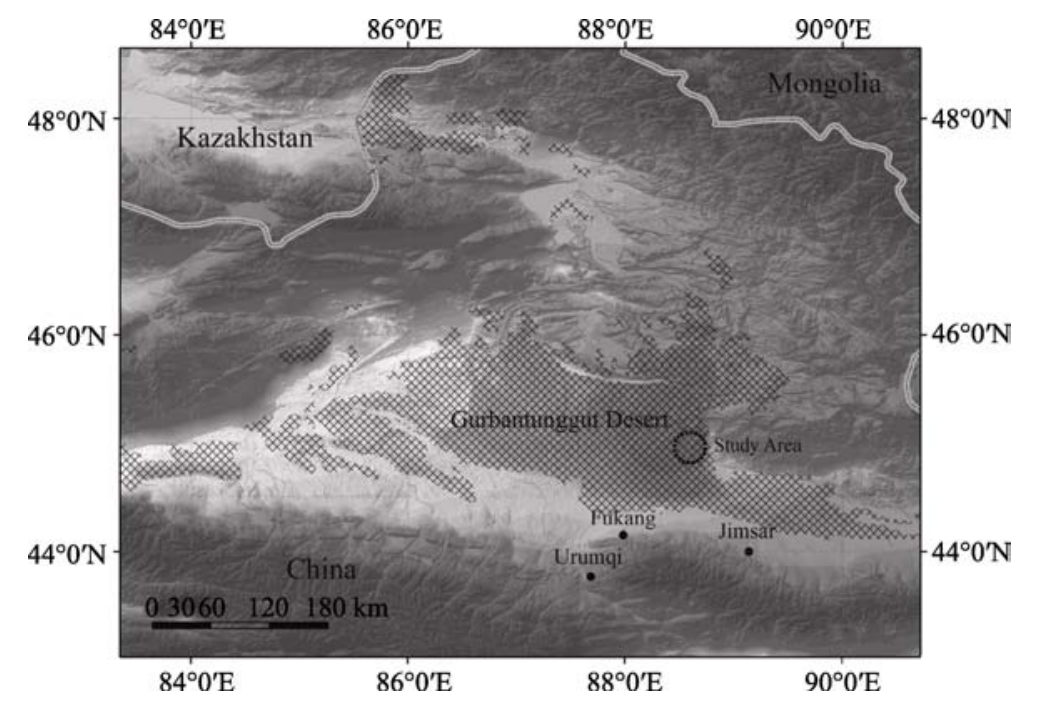

Figure 1 Geographical location of Gurbantunggut Desert (area with grids) and study area (area within a circle). (Source: Database of the Institute of Agricultural Resources and Regional Planning, Chinese Academy of Agricultural Sciences, 1999)

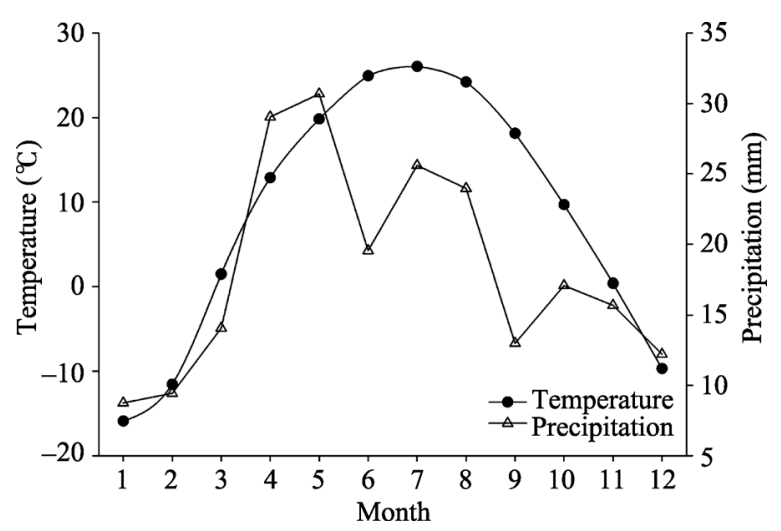

Figure 2 Average monthly temperature and precipitation of Jimsar County (where the study area was located) from 2001 to 2009 


\subsection{Field sampling}

Field sampling was conducted in July, a season when soil water is at average level for the year (Zhu et al., 2008; Qian and Wu, 2010). A preliminary investigation on plant distribution over the study area (about $8 \mathrm{~km}$ north-south and $12 \mathrm{~km}$ west-east) was firstly conducted. The typical topographies in the study area are flat ground, gentle slope and large sand dunes. According to vegetation-topography interaction (Qiu et al., 2013) and methods for vegetation evaluation (Qian et al., 2004; Ma et al., 2011), typical sites with representative vegetation of 4 terrains (flat ground, gently sloping area, middle part of the slope of a dune and top of a dune) were selected. The location of the four sites were $44^{\circ} 95^{\prime} \mathrm{N}, 88^{\circ} 70^{\prime} \mathrm{E} ; 44^{\circ} 93^{\prime} \mathrm{N}$, $88^{\circ} 54^{\prime} \mathrm{E} ; 45^{\circ} 00^{\prime} \mathrm{N}, 88^{\circ} 55^{\prime} \mathrm{E}$; $44^{\circ} 93^{\prime} \mathrm{N}, 88^{\circ} 63^{\prime} \mathrm{E}$, respectively. Five plots with $50 \mathrm{~m}$ interval in a line were set in each site. Plots $1-5,6-10,11-15$ and 16-20 were on the flat ground, gently sloping area, middle part of the slope of a dune and top of a dune, respectively. The size of a plot was $5 \times 5 \mathrm{~m}$. Vegetation coverage of each plot was estimated by an expert. Plant height and number of every species in each plot were recorded. Plant density of a plot was calculated as the number of all plants divided by the area of a plot $\left(25 \mathrm{~m}^{2}\right)$. Above-ground biomass of all plants was harvested and weighed. The plants were oven dried at $80^{\circ} \mathrm{C}$ for 3 days and the dry weight and water content were determined. The averages of all species in each plot were calculated.

Soil was sampled at depths of 0-5, 17.5-22.5 cm (hereafter as $20 \mathrm{~cm}$ ) and $47.5-52.5 \mathrm{~cm}$ (hereafter as $50 \mathrm{~cm}$ ). The water content of each sample was measured using gravimetric method. Soil samples were analyzed for total organic carbon by the wet digestion method (Walkley and Black, 1934).Total nitrate was measured with an Autokjeldahl Unit (Buchi K-370, BüchiLabortechnik AG, Switzerland).Total phosphate was measured with a spectrophotometer (UV-2550, Shimadzu, Japan). Total potassium (K) and soluble sodium (Na), calcium (Ca) and magnesium (Mg) were measured with an atomic absorption spectrophotometer (PE 5100 PC, PerkinElmer Inc, USA) (Zhang et al., 2000). Soil electrical conductivity (EC) was measured using a portable conductivity meter (Cole-Parmer Instrument Company, USA).

\subsection{Vegetation classification}

Importance values (IV) were calculated for all species for each sampling plot as the sum of relative height (\% of height) + relative density (\% of total individual number) + relative biomass (\% of total biomass) and then divided by three. Importance value, therefore, reflects dominance in the plot. A previous study also showed that the IV is a reliable index for characterizing the vegetation in Gurbantunggut Desert (Zhang et al., 2003). The IV data matrix consisting of 20 sites and all species were classified by Two-way Cluster Analysis to determine the vegetation groups (McCune and Mefford, 1999).

Based on the classification, the vegetation coverage, plant density and water content of plants in each vegetation group were summarized. They were calculated as the averages of all plots in each vegetation group.

\subsection{Canonical correspondence analysis}

The species-soil relationship of multi-species communities can be analyzed by the methods 
of constrained ordination, i.e. canonical correspondence analysis (CCA) (Hyvönen et al., 2005). All data variables were assessed for normality (ter Braak, 1986) prior to the CCA analysis, and arc-sin transformation was used on the soil water data (Abd el-Ghani and Amer, 2003). Eighteen soil variables, including soil water content, EC, total N, total P, total K and organic matter in each soil layer, were used. The PC-ORD 5.0 (McCune and Mefford, 1999) was used for classification and ordination analysis.

\subsection{Species diversity index}

Species diversity index was calculated using species number data (McCune and Mefford, 1999) to understand species diversity in different vegetation groups. Richness (S), Evenness $(E)$, Shannon diversity $\left(H^{\prime}\right)$ and Simpson's index $(D)$ were calculated.

\section{Results}

\subsection{Classification}

Two-way Cluster Analysis indicated that the vegetation of the study area could be divided into 3 groups (Figure 3). The first group (Group 1) was dominated by the shrub species,

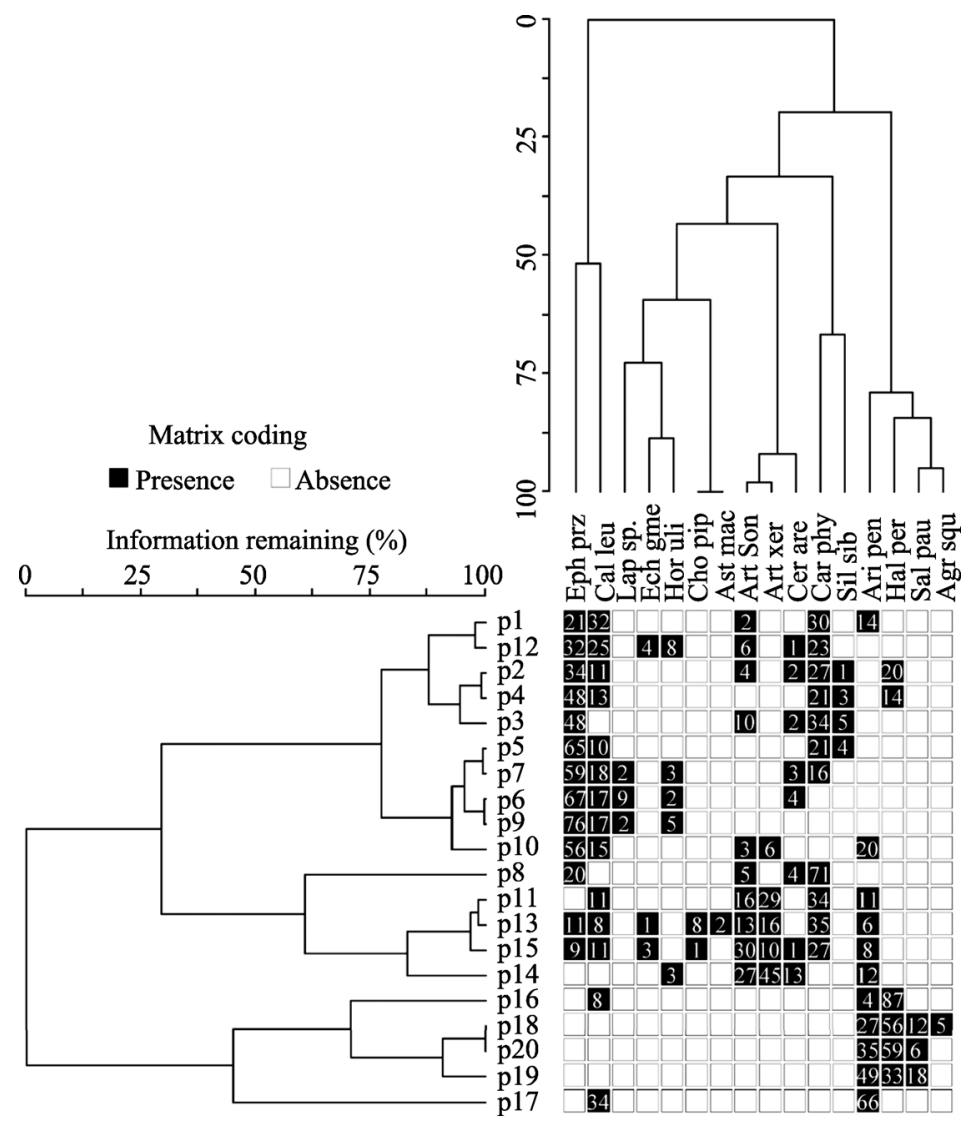

Figure 3 Dendrogram derived from Two-way Cluster Analysis of the vegetation data collected at Gurbantunggut Desert; p1-p20 represents plot numbers. The abbreviations for key species are: Eph prz (Ephedra przewalskii), Art son (Artemisia songorica), Art xer (Artemisia xerophytica), Car phy (Carex physodes), Hal per (Haloxylon persicum). Data in black grids are importance value of a species in a plot 
Ephedra przewalskii and the grass species, Carex physodes mainly in areas of flat grounds and gentle slopes. The second group (Group 2) was dominated by C. physodes, Artemisia songorica and A. xerophytica mainly on the slope of sand dunes. The third group (Group 3) was dominated by the shrub species, Haloxylon persicum mainly on the top of sand dunes.

\subsection{Species diversity}

Vegetation coverage decreased significantly in the order of Groups $1 \rightarrow 2 \rightarrow 3$. i.e. from flat ground to the top of dune (Table 1). The plant density, however, showed no significant difference between Group 1 and 2 but there was a significant decrease in Group 3. The plant water contents were about $40 \%$ and there was no significant difference among vegetation groups. Species richness showed the same tendency as plant density. There was little difference in other diversity indexes among the three groups. Generally, diversity indexes and species richness seemed low in Gurbantonggut Desert compared with non-desert areas.

Table 1 Summary of vegetation coverage, plant density, plant water contents and species diversity index in the east central part of Gurbantunggut Desert. Values in column with different letters are significantly different at $p<0.05$. $S, E, H^{\prime}$ and $D$ represents richness, Shannon index, evenness and Simpson's index of diversity, respectively.

\begin{tabular}{cccccccc}
\hline $\begin{array}{c}\text { Vegetation } \\
\text { group }\end{array}$ & $\begin{array}{c}\text { Coverage } \\
(\%)\end{array}$ & $\begin{array}{c}\text { Density } \\
\left.(\text { number m })^{-1}\right)\end{array}$ & $\begin{array}{c}\text { Plant water } \\
\text { content (\%) }\end{array}$ & $S$ & $E$ & $H^{\prime}$ & $D$ \\
\hline Group 1 & $24^{\mathrm{a}}$ & $29^{\mathrm{a}}$ & 40 & $5.3^{\mathrm{a}}$ & 0.38 & 0.64 & 0.37 \\
Group 2 & $16^{\mathrm{b}}$ & $23^{\mathrm{a}}$ & 41 & $6.2^{\mathrm{a}}$ & 0.43 & 0.75 & 0.36 \\
Group 3 & $10^{\mathrm{c}}$ & $3^{\mathrm{b}}$ & 44 & $3^{\mathrm{b}}$ & 0.57 & 0.67 & 0.38 \\
\hline
\end{tabular}

Means in the same column followed by different letters differ significantly according to Duncan's multiple range test.

\subsection{Soil condition}

Soil conditions were summarized based on the vegetation group classified by Two-way Cluster Analysis. Soil water contents in all vegetation groups were very low, especially in the surface soil (Table 2). In general, the deeper the soil, the higher the water content was.

Table 2 Soil parameters of the three vegetation groups in the east central part of Gurbantunggut Desert at surface, 20 and $50 \mathrm{~cm}$ soil depth. Data are means. Different letters within 3 vegetation groups at each depth for each parameter show significant difference at $p<0.05$

\begin{tabular}{|c|c|c|c|c|c|c|c|c|c|}
\hline & \multicolumn{3}{|c|}{ Surface } & \multicolumn{3}{|c|}{$20 \mathrm{~cm}$} & \multicolumn{3}{|c|}{$50 \mathrm{~cm}$} \\
\hline & \multicolumn{3}{|c|}{ Vegetation group } & \multicolumn{3}{|c|}{ Vegetation group } & \multicolumn{3}{|c|}{ Vegetation group } \\
\hline & 1 & 2 & 3 & 1 & 2 & 3 & 1 & 2 & 3 \\
\hline Soil water (\%) & $0.152^{\mathrm{a}}$ & $0.186^{\mathrm{a}}$ & $0.042^{\mathrm{b}}$ & $0.353^{\mathrm{a}}$ & $0.450^{\mathrm{a}}$ & $0.108^{\mathrm{b}}$ & $0.456^{\mathrm{ab}}$ & $0.664^{\mathrm{a}}$ & $0.256^{\mathrm{b}}$ \\
\hline $\mathrm{EC}\left(\mathrm{mS} \mathrm{cm}{ }^{-1}\right)$ & $0.050^{\mathrm{a}}$ & $0.051^{\mathrm{a}}$ & $0.028^{\mathrm{b}}$ & $0.047^{\mathrm{a}}$ & $0.044^{\mathrm{a}}$ & $0.022^{\mathrm{b}}$ & $0.058^{\mathrm{a}}$ & $0.065^{\mathrm{a}}$ & $0.022^{\mathrm{b}}$ \\
\hline Organic matter $\left(\mathrm{mg} \mathrm{kg}^{-1}\right)$ & $1960^{\mathrm{a}}$ & $1820^{\mathrm{a}}$ & $600^{\mathrm{b}}$ & $1240^{\mathrm{a}}$ & $1120^{\mathrm{ab}}$ & $800^{\mathrm{b}}$ & $1110^{\mathrm{a}}$ & $1020^{\mathrm{a}}$ & $660^{\mathrm{b}}$ \\
\hline $\mathrm{N}\left(\mathrm{mg} \mathrm{kg}^{-1}\right)$ & $128^{\mathrm{a}}$ & $80^{\mathrm{b}}$ & $17^{c}$ & $91^{\mathrm{a}}$ & $44^{\mathrm{b}}$ & $8^{\mathrm{b}}$ & $84^{\mathrm{a}}$ & $34^{\mathrm{b}}$ & $4^{\mathrm{b}}$ \\
\hline $\mathrm{P}\left(\mathrm{mg} \mathrm{kg}^{-1}\right)$ & $340^{\mathrm{a}}$ & $372^{\mathrm{a}}$ & $188^{\mathrm{b}}$ & $265^{\mathrm{a}}$ & $322^{\mathrm{a}}$ & $186^{\mathrm{b}}$ & $283^{\mathrm{a}}$ & $312^{\mathrm{a}}$ & $186^{\mathrm{b}}$ \\
\hline $\mathrm{K}\left(\mathrm{mg} \mathrm{kg}^{-1}\right)$ & $14180^{\mathrm{a}}$ & $13880^{\mathrm{a}}$ & $14100^{\mathrm{a}}$ & $14470^{\mathrm{a}}$ & $14040^{\mathrm{a}}$ & $14420^{\mathrm{a}}$ & $14240^{\mathrm{a}}$ & $14320^{\mathrm{a}}$ & $14660^{\mathrm{a}}$ \\
\hline $\mathrm{Na}\left(\mathrm{mg} \mathrm{kg}^{-1}\right)$ & $30^{\mathrm{ab}}$ & $35^{\mathrm{a}}$ & $22^{\mathrm{b}}$ & $45^{\mathrm{a}}$ & $39^{\mathrm{a}}$ & $21^{\mathrm{a}}$ & $56^{\mathrm{a}}$ & $81^{\mathrm{ab}}$ & $19^{\mathrm{b}}$ \\
\hline $\mathrm{Ca}\left(\mathrm{mg} \mathrm{kg}^{-1}\right)$ & $44^{\mathrm{a}}$ & $43^{\mathrm{a}}$ & $22^{\mathrm{b}}$ & $51^{\mathrm{a}}$ & $48^{\mathrm{a}}$ & $18^{\mathrm{b}}$ & $47^{\mathrm{a}}$ & $41^{\mathrm{a}}$ & $21^{\mathrm{b}}$ \\
\hline $\operatorname{Mg}\left(\mathrm{mg} \mathrm{kg}^{-1}\right)$ & $10^{\mathrm{a}}$ & $7^{\mathrm{a}}$ & $3^{\mathrm{b}}$ & $10^{\mathrm{a}}$ & $10^{\mathrm{a}}$ & $1^{\mathrm{b}}$ & $8^{\mathrm{a}}$ & $7^{\mathrm{a}}$ & $2^{\mathrm{b}}$ \\
\hline
\end{tabular}

For each vegetation group, means in the same row followed by different letters differ significantly according to Duncan's multiple range test. 
Soil water under vegetation Group 3 was significantly lower than that in other two vegetation groups at all soil depths, while Groups 1 and 2 had no significant difference. The EC, organic matter, total $\mathrm{P}$ and soluble $\mathrm{Na}, \mathrm{Ca}, \mathrm{Mg}$ varied very similarly with soil water content among the three groups. Total $\mathrm{K}$ had very close values across vegetation groups and soil depth. The most remarkable soil factor was total $\mathrm{N}$, which decreased sharply from surface to deeper soil layers in each vegetation group. It significantly decreased in the order of Group $1 \rightarrow 2 \rightarrow 3$ in surface soil.

\subsection{Ordination}

The first three axes accounted for about $70 \%$ of the variation in soil factor data (Table 3), suggesting that these axes were the most important determinants of the variation in this area. The factors that highly correlated with axis 1 were total $\mathrm{P}$, organic matter and total $\mathrm{N}$ in the surface soil, and soil electrical conductivity at the $20 \mathrm{~cm}$ depth. The main correlates of axis 2 were soil water at the $50 \mathrm{~cm}$ depth and total $\mathrm{P}$ at the $20 \mathrm{~cm}$ depth (Table 4). Figure 4 shows that vegetation Group 1, at the bottom right, had strong positive correlations with the factors that also positively correlated with axis 1 and soil electrical conductivity in the surface and $50 \mathrm{~cm}$ layers. Surface soil water content also affected the distribution of the plants. Conversely, on the left side, vegetation Group 3 was negatively correlated with these factors. At the upper right, vegetation Group 2 correlated positively with axis 2, soil water in the $50 \mathrm{~cm}$ and total $\mathrm{P}$ in the $20 \mathrm{~cm}$ depths. Also, this

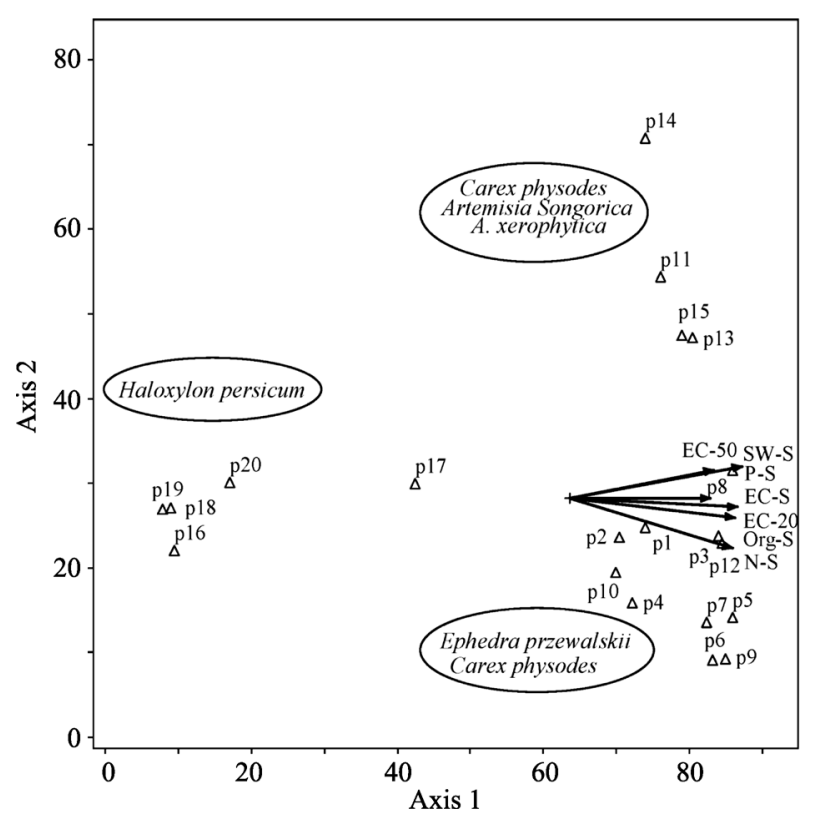

Figure 4 Canonical correspondence analysis (CCA) plots ordination of the plots in Gurbantunggut Desert, China. The vectors represent environmental variables. The length of the vector is proportional to its importance and the angle between a vector and each axis is related to its correlation with the axis. Variables with a correlation coefficient higher than 0.45 are presented. Other abbreviations are as defined in Table 4. group positively correlated with soil factors of axis 1 but at a weaker scale than Group 1 .

Table 3 Summary statistics of the three canonical correspondence analysis (CCA) ordinations in the east central part of Gurbantunggut Desert

\begin{tabular}{cccc}
\hline & Axis 1 & Axis 2 & Axis 3 \\
\hline Eigenvalues & 0.744 & 0.478 & 0.254 \\
Variance explained (\%) & 34.7 & 22.3 & 11.9 \\
Cumulative explained (\%) & 34.7 & 57 & 68.9 \\
Pearson correlation & 0.997 & 0.998 & 0.963 \\
\hline
\end{tabular}


Table 4 Canonical coefficients and inter-set correlations of environmental variables with the first three axes of Canonical correspondence analysis (CCA) for the data set from Gurbantunggut Desert. The abbreviations are SW: soil water, EC: electrical conductivity, Org: organic matter, $-\mathrm{S}$ : 0-5 cm soil, -20 : $20 \mathrm{~cm}$ soil depth, -50 : $50 \mathrm{~cm}$ soil depth.

\begin{tabular}{|c|c|c|c|c|c|c|}
\hline \multirow{2}{*}{ Variable } & \multicolumn{3}{|c|}{ Canonical coefficients } & \multicolumn{3}{|c|}{ Inter-set correlations } \\
\hline & Axis 1 & Axis 2 & Axis 3 & Axis 1 & Axis 2 & Axis 3 \\
\hline SW-S & 1.689 & 1.451 & -0.266 & 0.7 & 0.218 & -0.199 \\
\hline SW-20 & -0.085 & -0.067 & 0.057 & 0.574 & 0.296 & -0.178 \\
\hline SW-50 & -1.034 & -0.346 & -0.014 & 0.487 & 0.556 & 0.005 \\
\hline EC-S & -0.857 & -0.48 & 0.164 & 0.684 & 0.002 & -0.388 \\
\hline EC-20 & -0.58 & 0.267 & -1.507 & 0.816 & -0.062 & -0.19 \\
\hline EC-50 & 0.391 & 0.219 & -0.451 & 0.699 & 0.214 & -0.03 \\
\hline Org-S & 1.111 & 0.937 & -0.563 & 0.806 & -0.148 & -0.234 \\
\hline Org-20 & -1.039 & -0.631 & 0.165 & 0.496 & -0.235 & -0.253 \\
\hline Org-50 & 0.186 & 0.331 & -0.557 & 0.593 & -0.165 & -0.076 \\
\hline $\mathrm{N}-\mathrm{S}$ & 0.692 & -0.383 & 0.329 & 0.793 & -0.383 & -0.262 \\
\hline $\mathrm{N}-20$ & 0.143 & -0.327 & 0.422 & 0.616 & -0.395 & -0.189 \\
\hline $\mathrm{N}-50$ & 0.665 & 0.363 & 0.354 & 0.609 & -0.449 & -0.105 \\
\hline P-S & -0.901 & -1.656 & 2.251 & 0.841 & 0.245 & 0.053 \\
\hline P-20 & 2.611 & 2.213 & 0.022 & 0.476 & 0.536 & -0.113 \\
\hline P-50 & -2.112 & -1.801 & -0.751 & 0.458 & 0.397 & -0.033 \\
\hline K-S & -1.615 & -1.019 & -0.676 & 0.043 & -0.463 & -0.401 \\
\hline $\mathrm{K}-20$ & 0.67 & 0.058 & 0.683 & 0.05 & -0.46 & -0.243 \\
\hline $\mathrm{K}-50$ & 0.283 & 0.065 & -0.31 & 0.015 & -0.333 & -0.097 \\
\hline
\end{tabular}

\section{Discussion}

All 16 plants found in the study area belong to xerophytes, which are typical desert species (Figure 3). Vegetation classification indicated three plant communities in the study area. The total number of species and communities found in our study area were less than those in the whole southern part (Zhao et al., 2010; Song et al., 2011). This was because the sizes of the areas investigated were different. However, these numbers were also much less (1/4 to 1/3) than those for similar or even smaller areas in the southern part of the desert at similar longitudes (Zhang et al., 2003; Tang et al., 2010).This result indicates a decrease in species richness from the southern border to the east central part of the desert. The same tendency was also reported for a small distance of $10 \mathrm{~km}$ within the southern border of the desert (Tang et al., 2010). Besides, vegetation coverage in our study area was lower than that in the border of the desert (Song et al., 2011). The dominant plan species found in this study were all different from those in the southern border at similar longitude (Zhang et al., 2003; Tang et al., 2010), which implies that vegetation distinctly changes from border to the center of the desert.

In this study, dominant plant communities were different at different terrains (flat ground 
with gentle slope, slope, top of dune) indicating that topography affects the composition of plant communities. This may be because the environments (soil water, soil nutrients, soil texture, wind speed, etc.) of different terrains were different (Tang et al., 2010) and also because different plants have different niche requirements. From the aspect of plant growth in general, the top of the dune had the worst soil conditions among all terrains (Table 2). The sole significant difference between steep slope and ground with gentle slopes was the amount of soil nitrogen (Table 2). This result showed the significance of soil nitrogen in the establishment of plant communities in this area.

Soil conditions of the studied area were very dry, very poor in nutrients, organic matter and soluble salts (Table 2), showing typical desert features. It has been reported that many places in the southern part of the desert are with high salinity (Xu, 1998; Qian and Wu, 2010), but there was no soil salinization in our study area. The non-saline soil in this study area may be due to its relatively far distance from the oasis compared with other studies. The higher amount of organic matter, nitrogen and phosphate in surface than deeper layers in flat ground with gentle slope and slope may be ascribed to the crust formed on the surface of the soil (Zhang et al., 2010). Another reason may be the processes of mineral materials, organic matter and other nutrients moving from top down to the ground through wind erosion ( $\mathrm{Li}$ et al., 2008). However, nutrient contents at different depths were similar at the top of the dune (Table 2). This may be due to severe sand mobilization on the top of the dune (Wang et al., 2005), which makes the formation of the crust difficult. The lowest value of almost all soil factors on the top of the dune may also be attributed to the severe sand mobilization, which reduced water and nutrient deposition. The significant differences in soil factors between top of the dune and lower part of dune (ground with gentle slope) in this study are consistent with previous reports on the southern part of the desert (Li et al., 2010).

The CCA satisfactorily assessed the species-soil relations in the studied area (Tables 3 and 4, Figure 4). The distribution of plant species was strongly correlated with soil factors of water content, organic matter, EC and nutrients. Differences in properties of surface soil and EC across layers induced a separation of plant communities, Groups 1 and 3. The dominant plants of Group 1 were Ephedra przenalskii and Carex physodes (Figures 3 and 4). E. przenalskii is a shrub with well-developed root system (Liu, 1985). It is usually a dominant species in areas with relatively better water condition (Liu, 1985). These characteristics possibly contributed to its dominance in flat ground and gentle slope (Figure 3) where water contents were relatively high (Qian and Wu, 2010). One of the main widely distributed species in the southern part of the desert is $E$. distachya, which belongs to the same genus as $E$. przenalskii. However, this species was not found in our study area. There is little report explaining the different distribution area of these two similar species in the same desert.

Another dominant species of Group 1 was Carex physodes, a herbaceous plant with creeping roots developed in the shallow layer of the soil (Liu, 1985; Wang et al., 2006). This plant is very sensitive to water condition and its presence is positively correlated with water content in the soil (Wang et al., 2006; Chen et al., 2008). The dominance of this species in flat ground and gentle slope may be attributed to the above characteristics because the soil condition in the flat with gentle slope matches its characteristics (Table 2 and Figure 4). This species is also widely distributed in the southern part of the desert, indicating its wide adaptability. 
The dominant plant in Group 3 was Haloxylan persicum. This plant is a shrub or small arbor with well-developed root system distributed widely and deeply (Jia and Lu, 2005). It has very high water use efficiency (165.6 g) and high resistance to wind and sand strike. Sand burial, conversely, enhances its growth (Jia and Lu, 2005). The adaptation of this plant to the most severe environment, the top of dune in the desert, may attribute to its above eco-physiological characteristics. Species of $\mathrm{H}$. ammodendron, which belongs to the same genus as $H$. persicum, is a dominant species in the southern part of the desert. The most important soil factor for the different distribution area of these two species may be soil salinity (Jia and Lu, 2005). The salinization in the southern part of the desert may result in the absence of $H$. persicum since it is very sensitive to salinity (Jia and Lu, 2005).

The similarity in soil condition between dune slope and flat ground with gentle slope may be one of the reasons for the dominance of Carex physodesin also in dune slope (Table 2, Figures 3 and 4). This also indicates its high adaptability. Two other dominant species of dune slope were of the Artermisia genus. Plants of Artermisia genus showed increased growth and density in arid sandy desert with an increase in soil phosphorus (Zhao et al., 2012). Our study also showed a positive correlation of A. songorica and A. xerophytica with soil phosphorus in the $20 \mathrm{~cm}$ depth (axis 2, Figure 4). Among the three terrains, total soil phosphorus was the highest in the dune slope (Table 2), which may also contribute to the dominance of Artermisia species in the dune slope.

The variation in the species explained by the three CCA axes was about $70 \%$ for the area (Table 3), indicating that some explanatory site variables may exist outside our studied parameters. Among soil factors, soil texture affects the distribution of plant species by influencing moisture availability, aeration and distribution of plant roots (El-Sheikh and Yousef, 1981). The mobilization and accumulation of sands in the desert may result in different soil texture in different terrains. Therefore, soil texture is expected to improve the explanation of CCA axes and is thus recommend to be considered in similar studies in future.

\section{Conclusions}

(1) Plant species in the east central part of Gurbantunggut Desert are of typical desert vegetation. Three plant communities were found in the area. Total number of plant species decreased by about $70 \%$ from the southern border to the center of the desert in the eastern part and the dominate plants were all different with those in the southern part.

(2) Soil conditions of the studied area showed typical desert features. Soil nitrogen significantly affects the establishment of plant communities. The distribution of plant species was strongly correlated with the soil factors of water content $(0.70)$, organic matter $(0.81)$, EC (0.82), N (0.79) and P (0.84).

(3) The dominant plant species in flat ground with gentle slopes were Ephedra przenalskii and Carex physodes; those in the slope of a dune were $C$. physodes, Atermisia songorica and A. xerophytica; those on the top of the dune were Haloxylan persicum. The eco-physiological characteristics of these plant species were consistent with their environments.

(4) The CCA explained the species-soil relations by about $70 \%$ in the studied area. Soil texture is suggested to be included in the CCA in similar studies in future. 


\section{References}

Abd el-Ghani M M, Amer W M, 2003. Soil-vegetation relationships in a coastal desert plain of southern Sinai, Egypt. Journal of Arid Environments, 55(4): 607-628.

Fan L L, Li Y, Tang L S et al., 2013. Combined effects of snow depth and nitrogen addition on ephemeral growth at the southern edge of the Gurbantunggut Desert, China. Journal of Arid Land, 5(4): 500-510.

Chen Z C, Shi Z Y, Tian C Y et al., 2008. Diversity and spatial distribution characteristics of ephemeral plants germinated in autumn in the southern edge of Gurbantunggut Desert. Journal of Anhui Agricultural Sciences, 36(5): 2016-2018. (in Chinese)

El-Sheikh A M, Yousef M M, 1981. Halophytic and xerophytic vegetation near Al-Kharg springs. Journal of Colloid Science University Riyadh, 12(1): 5-12.

Fan L L, Ma J, Wu L F et al., 2012. Response of the herbaceous layer to snow variability at the south margin of the Gurbantunggut Desert of China. Chinese Journal of Plant Ecology, 36(2): 126-135. (in Chinese)

Hyvönen T, Holopainen J, Tiainen J, 2005. Detecting the spatial component of variation in the weed community at the farm scale with variation partitioning by canonical correspondence analysis. Weed Research, 45(1): 48-56.

Jafari M, Chahouki M A Z, Tavili A et al., 2004. Effective environmental factors in the distribution of vegetation types in Poshtkouh rangelands of Yazd Province (Iran). Journal of Arid Environments, 56(4): 627-641.

Ji F, Ye W, Wei W, 2000. Preliminary study on the formation causes of the fixed and semi-fixed dunes in Gurbantunggut Desert. Arid Land Geography, 23(1): 32-36. (in Chinese)

Jia Z Q, Lu Q, 2005. Haloxylon. Beijing: China Environmental Science Press, 9-11.

Li C J, Li Y, Ma J et al., 2010. Spatial heterogeneity of soil chemical properties between Haloxylon persicum and Haloxylon ammodendron populations. Journal of Arid Land, 2(4): 257-265.

Li C J, Li Y, Ma J A, 2011. Spatial heterogeneity of soil chemical properties at fine scales induced by Haloxylon ammodendron (Chenopodiaceae) plants in a sandy desert. Ecological Research, 26(2): 385-394.

Li J, Okin G S, Alvarez L et al., 2008. Effects of wind erosion on the spatial heterogeneity of soil nutrients in two desert grassland communities. Biogeochemistry, 88(1): 73-88.

Liu Y X, 1985. Flora in Desertis Reipublicae Populorum Sinarum. Tomus 1. Beijing: Science Press, 183-185: 342-343. (in Chinese)

Ma X D, Chen Y N, Zhu C G et al., 2011. The variation in soil moisture and the appropriate groundwater table for desert riparian forest along the Lowre Tarim River. Journal of Geographical Sciences, 21(1): 150-162.

McCune B, Mefford M J, 1999. Multivariate Analysis of Ecological Data. Version 5.0. MjM Software, Gleneden Beach, Oregon, USA.

Ozinga W A, Schaminee J H J, Bekker R M et al., 2005. Predictability of plant species composition from environmental conditions is constrained by dispersal limitation. Oikos, 108(3): 555-561.

Qian Y B, Lei J Q, Wu Z N, 2002. Vertical Distribution of Aeolian Sandy Soil Moisture and Recovery of Damaged Vegetation in Gurbantunggut Desert. Journal of Arid Land Resources and Environment, 16(4): 69-72. (in Chinese)

Qian Y B, Wu Z N, 2008. Vegetation patterns and species-environment relatioships in the Gurbantunggut Desert of China. Journal of Geographical Sciences, 18(4): 400-414.

Qian Y B, Wu Z N, 2010. Environments of Gurbantunggut Desert. Beijing: Science Press, 67-69.

Qian Y B, Wu Z N, Zhang L Y et al., 2004. Impact of habital heterogeneity on plant community pattern in Gurbantunggut Desert. Journal of Geographical Sciences, 14(4): 447-455.

Qian Y B, Wu Z N, Zhang L Y et al., 2007. Spatial patterns of ephemeral plants in Gurbantunggut Desert. Chinese Science Bulletin, 52(22): 3118-3127.

Qiu B W, Zeng C Y, Chen C C et al., 2013. Vegetatin distribution pattern along altitudinal gradient in subtropical mountainous and hilly river basin, China. Journal of Geographical Sciences, 23(2): 247-257.

Song Y Y, Zhou C B, Zhang W H, 2011. Vegetation coverage, species richness, and dune stability in the southern part of Gurbantunggut Desert. Ecological Research, 26(1): 79-86.

SPSS, 2000. SPSS 10.0 for Windows. SPSS Inc USA. 
Tang J, Li X, Zhao Z et al., 2010. Response of plant diversity in desert and dominant population spatial pattern to the environment. Xinjiang Agricultural Science, 47(10): 2084-2090. (in Chinese)

ter Braak C J F, 1986. Canonical correspondence analysis: A new eigenvector technique for multivariate direct gradient analysis. Ecology, 67(5): 1167-1179.

Walkley A, Black I A, 1934. An examination of degtjareff method for determining soil organic matter and a proposed modification of the chromic acid titration method. Soil Science, 37(1): 29-38.

Wang T, 2003. Desert and desertification in China. Shijiazhuang: Hebei Science and Technology Publishing House, 641-648. (in Chinese with English catalogue)

Wang X Q, Jiang J, Lei J Q et al., 2003. Distribution of ephemeral plants and their significance in dune stabilization in Gurbantunggut Desert. Jounal of Geographical Sciences, 13(3): 323-330.

Wang X Q, Jiang J, Wang Y C et al., 2006. Responses of ephemeral plants to water and temperature in southern part of Gurbantonggut Desert. Chinese Science Bulletin, 51: 110-116. (in Chinese)

Wang X Q, Wang T, Jiang J et al., 2005. On the sand surface stability in the southern part of Gurbantunggut Desert. Science in China Series D: Earth Sciences, 48(6): 778-785. (in Chinese)

Wang X Q, Zhang Y M, Jiang J et al., 2009. Effects of spring-summer grazing on longitudinal dune surfac in southern Gurbantunggut Desert. Journal of Geographical Sciences, 19: 299-308.

Wei W S, He Q, Liu M Z, 2003. Climate change and the desert environment in Junggar Basin, Xinjiang, China. Journal of Desert Research, 23(2): 101-105. (in Chinese)

Xie J B, Liu T, 2010. Characterization of spatial scaling relationships between vegetation pattern and topography at different directions in Gurbantunggut Desert, China. Ecological Complexity, 7(2): 234-242.

$\mathrm{Xu} \mathrm{P,} \mathrm{1998.} \mathrm{Glassland} \mathrm{and} \mathrm{Water-salt-plant} \mathrm{System} \mathrm{and} \mathrm{Its} \mathrm{Optimized} \mathrm{Ecological} \mathrm{Model} \mathrm{in} \mathrm{Desert} \mathrm{Area} \mathrm{of}$ Xinjiang. Beijing: Science Press, 52-80. (in Chinese)

Zhang D Y, Liu H L, Shi X et al., 2011. Limitations on the recruitment of the rare sand shrubby legume Eremosparton songoricum (Fabaceae) in Gurbantunggut Desert, China. Journal of Arid Land, 3(2): 75-84.

Zhang K, Li C J, Li Z S et al., 2013. Characteristics of mineral elements in shoots of three annual halophytes in a saline desert, Northern Xinjiang. Journal of Arid Land, 5(2): 244-254.

Zhang L J, Yue M, Zhang Y D et al., 2003. Characteristics of plant community species diversity of Oasis desert ecotone in Fukang, Xinjiang. Scientia Geographica Sinica, 23(3): 329-334. (in Chinese)

Zhang L Y, Chen C D, 2002. On the general characteristics of plant diversity of Gurbantunggut sandy desert. Acta Ecologica Sinica, 22(11): 1923-1932. (in Chinese)

Zhang Y M, Wu N, Zhang B C et al., 2010. Species composition, distributuion patterns and ecological functions of biological soil crusts in the Gurbantunggut Desert. Jounal of Arid Land, 2(3): 180-189.

Zhang Z, Chen G L, Zhang B G et al., 2000. The Lanmuchang Tl deposit and its environmental geochemistry. Science in China Series D-Earth Sciences, 43(1): 50-62.

Zhao H B, Liu T, Lei J Q et al., 2010. ßdiversity characteristic of vegetation community on south part of Gurbantunggut Desert and its interpretation. Acta Prataculturae Sinica, 19(3): 29-37. (in Chinese)

Zhao X L, He X D, Xue P P et al., 2012. Effects of soil stoichiometry of the CaCO3/available phosphorus ratio on plant density in Artemisia ordosica communities. Chinese Science Bulletin, 57(5): 492-499.

Zhu Y W, Chen Q M, Liu M X et al., 2008. Spatiotemporal distribution of moisture content in sand dunes of the unirrigated forestation along the southern marginal zone of Gurbantunggut Desert. Pratacultural Science, 25(12): 6-11. (in Chinese) 